\title{
A INFLUÊNCIA DOS ESTILOS DE LIDERANÇA NA MOTIVAÇÃO DOS COLABORADORES DE UMA AGÊNCIA BANCÁRIA NO PARANÁ, BRASIL
}

THE INFLUENCE OF LEADERSHIP STYLES IN MOTIVATING THE EMPLOYEES OF A BANK BRANCH IN PARANA, BRASIL

\author{
Herman Wies Lopes (FAEL) \\ Gleison Hidalgo Martins, Esp. (UFPR) \\ Elizabeth Zanetti, M.Sc. (FAEL)
}

\section{Palavras Chave \\ Sustentabilidade Organizacional; Motivação; Estilos de Liderança}

\section{Key Words}

Motivation; Leadership Styles; Organizational Sustainability

\section{RESUMO}

O artigo propõe-se a relacionar os estilos de liderança como geradores de sustentabilidade organizacional, delimitado no estudo da motivação e a influencia causada pelos estilos de lideranças sobre a motivação. Pretende-se definir o que é motivação e a possibilidade da utilização de diferentes estilos de liderança para motivar colaboradores, uma vez que colaboradores motivados geram maiores resultados. O estudo foi definido a partir da necessidade de esclarecer se os líderes tem influência sobre a motivação de seus liderados, sendo que na empresa pesquisada encontrou uma variação na motivação nos colaboradores. Diante dos fatos o objetivo é a identificação dos fatores que podem auxiliar a constante busca da sustentabilidade organizacional na empresa "Instituição Financeira de Pinhais". A metodologia científica utilizada para a pesquisa de campo através o método de pesquisa bibliográfico e quantitativo-descritivo de verificação de hipótese.

\section{ABSTRACT}

The article proposes to relate the leadership styles how organizational sustainability generators, delimiting in the study of the motivation and influence caused by leadership styles about the motivation. Intending to define what is motivation and the possibility of using different leadership styles to motivate the employees, once which are motivated generates greater results. The study was defined with start to necessity to clarify whether the leaders have influence on the motivation of their team, being that company researched was found variation on the motivation in employees. Before the facts the goal is to identify the factors that can assist the constant pursuit of organizational sustainability on the company "Instituição Financeira de Pinhais." The scientific methodology used was the search field through of the method of literature and quantitative descriptive research hypothesis verification. 


\section{INTRODUÇÃO}

O tema sobre os estilos de liderança como influenciadores na sustentabilidade organizacional surgiu após a observação dos colaboradores com os níveis de motivação. Esta variedade na motivação torna-se possível devido ao número de trinta membros sendo divididos entre onze gerentes e dezenove colaboradores. Havia no início a percepção de que a motivação dos colaboradores poderia ser influenciada pelos gestores através de seus estilos de lideranças. No entanto, por motivos de segurança não foi relatado o nome e endereço da empresa, assim como nenhuma identidade de colaborador.

A experiência datada do desde o ano de 2015 na empresa com o nome fictício de "Instituição Financeira de Pinhais", constatou-se que dentro dos setores da empresa, alguns colaboradores tinham maior motivação em relação aos outros colegas e consequentemente melhor desempenho. Ao perceber os diferentes níveis de desempenho destes colaboradores, surge o questionamento. Será que os gerentes possuem a responsabilidade de motivar seus liderados através de estilos e técnicas de liderança para a obtenção das metas da empresa?

Tendo como pesquisa a relação dos estilos de liderança dos gestores como fonte de motivação, este artigo desenvolveu-se a partir de uma pesquisa bibliográfica sobre os principais temas que norteiam a linha de pesquisa. Utilizando-se de livros e artigos científicos publicados em revistas eletrônicas e congressos possibilitaram a verificação sobre as fundamentações teóricas sobre o assunto e permitiram a produção de conceitos e objetivos através da pesquisa de campo, onde o objetivo principal é identificação dos fatores que podem auxiliar a constante busca da sustentabilidade organizacional na empresa "Instituição Financeira de Pinhais".

Para identificação dos fatores que podem auxiliar as lideranças na sustentabilidade organizacional, elaborou-se dentro de cinco secções, as quais serão disponibilizadas as informações explicativas sobre o tema abordado. A primeira secção trata-se da introdução onde conjuga-se a justificativa, a problemática, o objetivo e a metodologias de pesquisa a ser aplicada. A segunda secção aborda os conceitos encontrados na literatura sobre a sustentabilidade organizacional, motivação em relação com a liderança e os estilos de liderança. Em seguida, a terceira secção mostra a metodologia cientifica utilizada para encontrar as informações necessárias para o pleito. Já a quarta secção traz os resultados da pesquisa de campo efetuada na empresa em questão e a discussão dos resultados encontrados na pesquisa de campo, relacionando-os com a teoria tratada na segunda secção, tendo como resultado a conclusão sobre as dúvidas levantadas na pesquisa.

\section{REVISÃO BIBLIOGRÁFICA}

\subsection{Sustentabilidade organizacional}

Utilizada, na língua inglesa, desde o século XIII, a palavra sustentável originou-se do latim: "sus-tenere" e significa sustentar, suportar ou manter. A sustentabilidade passou a ser utilizada com maior frequência somente a partir dos anos 1980 (KAMIYAMA, 2011 apud BOLZAN, 2012). Mancini (2008) salienta que a sustentabilidade é uma gestão com responsabilidade social corporativa com foco sustentável caracterizada pelo dever ou obrigação ética para buscar o desenvolvimento pleno das partes interessada. $\mathrm{Na}$ abordagem do triple bottom line, conhecida como os 3 "P's" (People, Planet and Proift), gera outra característica, a organização sustentável, não se atém somente ao quesito lucro visando o desempenho econômico, social e ambiental (MUNCK, 2011). A sustentabilidade organizacional, em uma visão macro e pode ser percebida como uma característica que permite a permanência das empresas no mercado.

$\mathrm{Na}$ atual conjuntura, as organizações buscam uma maneira para destacar-se no mercado competitivo, que para (BARBIERI, 2016, p.6) “Cada vez mais se percebe o respeito pela diversidade e pelas necessidades psicológicas e motivacionais dos colaboradores das grandes organizações e também dos seus clientes". Na mesma linha de raciocínio (SILVEIRA, 2012) as empresas preocupam-se com a gestão dos recursos humanos, pois o capital humano correspondente aos conhecimentos e as competências do empregado e são colocados à disposição da organização, onde a maior importância é a capacidade da mobilização da geração e o compartilhamento como agregação desse valioso recuro aos processos da organização. Assim sendo, as organizações que não desenvolvem seu capital humano, não conseguem uma cultura de alta performance, pois para obtê-la é necessário uma gestão voltada para a avaliação de potencial, retenção e aumento do desempenho de talentos, desenvolvimento de liderança e investimento contínuo em treinamento e desenvolvimento de habilidades (BARBIERI, 2016, p.6). Na ótica de (FARAH et al., 2012, p.26) "O sucesso empresarial depende cada vez mais da capacidade dos gestores em criar, desenvolver, controlar e implementar ferramentas de gestão que tragam condições favoráveis ao ambiente organizacional".

Nestes ambientes surgem todos os dias novas ferramentas tecnológicas para a administração dos recursos 
humanos e de fato percebe-se que as novas tecnologias vão sempre provocar mudanças no ambiente social da organização (GONÇALVES, 1994). Porém Farah et al., (2012) reforça que este fato somente as ferramentas não são suficientes para a obtenção do resultado esperado e muitas vezes a melhor maneira para perceber o que pode ser alterado positivamente é simplesmente escutar o que seus colaboradores têm a dizer. O capital intelectual é o que detém o conhecimento necessário para a geração de riqueza na empresa (WERNER; WERNER, 2004).

Observa-se que o conceito de sustentabilidade organizacional vai além do lucro e da possibilidade de concluir negócios. Uma empresa sustentável promove a inclusão de todos os públicos envolvidos em seu meio (FARAH et al., 2012; MANCINI, 2012; KAMIYAMA, 2011 apud BOLZAN, 2012), ou seja, a organização que se perpetua no mercado tem a noção de seu papel como integrador cultural de seus colaboradores, clientes e meio ambiente. Sabe que é o agente transformador e que é o influenciado por seu público, então a empresa sustentável busca a otimização de seus variados recursos, integra seus produtos e serviços ás necessidades de seu público e está em constante adaptação em relação ao meio ambiente, respeitando valores e proporcionando uma real necessidade de existência para o meio que está inserida (FARAH et al., 2012).

\subsection{Motivação e a relação com a liderança}

Para Reeve (2011) o principal entendimento da diferenciação entre os homens e os animais vem da antiga Grécia, onde os filósofos dissertavam sobre a paixão e o conhecimento. Para Nabias (2008); Rabenhrst (2010) desde Aristóteles a definição, que o homem é um animal racional, incessantemente nos persegue e nos enaltece. Segundo Reeve (2011) Sócrates salientava, que a paixão não nos diferenciava dos animais e sim o conhecimento, pois é o que move o ser humano. Destes pensadores surge o posicionamento do indivíduo como senhor de seu comportamento motivacional. Ao homem ficava reservado a possibilidade de fazer filosofia, ciência, arte (NABAIS, 2008).

Posteriormente aos filósofos da antiguidade com os pensamentos sobre motivação foram ampliados pelos pensadores medievais e modernos como Descartes e Spinoza (REEVE, 2011). Estes últimos defendiam que as pessoas sofriam circunstâncias que não as controlavam, porém direcionavam seus esforços através dos desejos íntimos para atingir objetivos. Outras vertentes foram estudadas ao longo do tempo, como por exemplo, a teoria Hedonista, que defendia que a motivação do homem é regida pela busca do prazer. Na mesma linha do raciocínio
(MURRAY, 1983) o indivíduo estará motivado, quando na vivencia o prazer ou quando afastar-se dele quando não o obtém, buscando-o em outro momento.

Para Reeve (2011) outra teoria sobre o tema é a dos instintos, que relaciona a motivação humana por uma perspectiva darwinista, ou seja, com a evolução das espécies alguns instintos primitivos levam ás pessoas a agirem de determinada maneira. Logo buscam conceitos biológicos através da psicologia de Freud, o qual determinou que o instinto sexual fosse a primordial motivação das relações humanas (GRANZOTTO, 2007; REEVE, 2011). E a teoria do behaviorismo explicaria a motivação humana como resultante de experiências vividas durante sua vida (REEVE, 2011; COLARES, 2008).

$\mathrm{Na}$ atualidade quando pesquisamos sobre motivação dos homens, nos deparamos com a necessidade como fator de mudança de sua condição anterior. À medida que o homem satisfaz suas necessidades básicas, outras tomam o predomínio do comportamento indo até a realização pessoal (HESKETH; COSTA, 1980; Gomes; Michel, 2007). Na base da pirâmide estão as necessidades fisiológicas, acrescidos da dinâmica da homeostase e da ideia de Apetite (comer, beber, dormir, respirar, entre outros) (SAMPAIO, 2009). No próximo nível vem à segurança, que é condicionante para a prosperidade da espécie e livre de ameaças (GOMES; MICHEL, 2007). E em sequência, Maslow introduz que a necessidade de amor e relacionamento, posteriormente vem à estima e pôr fim as principais causas delas, a realização pessoal (SAMPAIO, 2009; OLIVEIRA; NOVAES, 2011).

$\mathrm{Na}$ teoria, todos os homens tem uma necessidade que buscam saciar e quando a realizam passam a ter outra necessidade em outro nível da pirâmide (REEVE, 2011). As motivações das pessoas surgem essencialmente pelas necessidades humanas decorrentes da natureza de seus instintos mais primitivos e como em uma pirâmide estas necessidades tornam-se conscientes à medida que sobem ao próximo degrau da pirâmide e isto transforma-se em um ciclo onde alcançada uma necessidade, automaticamente cria-se uma nova necessidade que é a razão da motivação da busca pelo ser humano (REEVE, 2011; SILVA et al., 2013).

Temos que compreender que a motivação é uma força que impulsiona alguém a atingir um objetivo. $O$ qual é a necessidade. A necessidade varia em intensidade, podendo ser alta, média ou baixa. Podendo uma necessidade de intensidade baixa deixar de existir, porque a motivação pode não ter força para realizar o impulso para a obtenção do resultado (REEVE, 2011). 
Uma das formas de aumento ou redução das necessidades é a homeostática, a qual trata dos motivos mais importantes, a sobrevivência dos homens, um dos exemplos, é a falta de comida, que levou o homem através dos tempos a caçar em variados territórios em busca de alimento e quando havia a falta do alimento o homem primitivo mudava-se até encontrar mais caça para sobreviver (SAMPAIO, 2009; REEVE, 2011). Porém esta motivação não pode ser estimulada no meio empresarial, e não devemos confundir a mudança de necessidades com a "reação típica" de estímulos ambientais, que ocorre quando um comportamento gera recompensas e torna-se prazeroso, e assim possivelmente se repetirá. Este tipo de reação típica é observado, mais comumente no comportamento de animais que são treinados para repetir padrões em troca de estímulos (REEVE, 2011).

Outra forma de instigar uma necessidade ocorre através dos motivos cognitivos, que envolvem os atos de pensar, refletir e analisar problemas, mas este estímulo perde a intensidade na medida em que ocorre a habituação, que é o processo de repetição do desafio que acaba gerando desinteresse com o passar do tempo (OLIVEIRA, 2006). Ha os motivos sociais, que aparecem quando os motivos básicos estão saciados, estes tem relação com os comportamentos inter-racionais e são bem aproveitados pelos gestores inteligentes e tornam-se poderosos motivos de aprendizagem (OLIVEIRA, 2006; LOMPSCHER, 1999 apud GODOI et al., 2011). Estes estímulos surgem dos relacionamentos interpessoais, como se divertir com pessoas, ganhar a aprovação de um grupo, competir com pares, e se reconhecer através dos semelhantes (OLIVEIRA, 2006).

Darwin situa os instintos sociais como os responsáveis pelo prazer que o sujeito sente ao conviver com seus pares, ao estabelecer trocas intelectuais, afetivas e materiais (OLIVEIRA, 2006 p.102).

Através de estímulos motivacionais é possível aumentar, diminuir ou instigar necessidades latentes. Cabe ao líder observar em seu grupo, os quais são as necessidades de seus colaboradores. E com este conhecimento poderá auxiliar seus liderados a satisfazer suas necessidades (OLIVEIRA, 2006). Quando os indivíduos convivem com líderes entusiasmados e aficionados, sentem-se mais seguros e confiantes e o ambiente de aprendizagem torna-se mais hostil e agradável (SKINNER; BELMONT, 1993).

Um líder deve observar a importância de todos os colaboradores na organização, pois o comportamento de um líder é o caminho para um bom ou mal resultado, um líder traz grandes resultados para a equipe (GIMENES et al., 2016), mas a observação e reconhecimento dos trabalhos realizados pelos colaboradores, pode gerar uma satisfação da necessidade de auto realização (OLIVEIRA, 2006).

\subsection{Estilos de lideranças}

A liderança vem sendo amplamente pesquisada por estudiosos de várias áreas, por tal prática por exercer influência sobre o pensamento e comportamento de outras pessoas (CASSIMIRO, 2013). Porque o líder é aquele que conquista seus liderados através de seu poder de influenciar pessoas (OLIVEIRA, PEREZ, 2015). A pesquisa mais relevante sobre estilos de liderança realizada no final da década de 1940, pela universidade Ohio State University. O estudo indagava sobre o comportamento dos líderes eficazes. Os pesquisadores estavam determinados a descobrir qual era o diferencial no comportamento dos líderes de sucesso. No início identificaram mais de mil vertentes e posteriormente reduziram para duas categorias principais, o comportamento centrado em tarefas, onde encontrou-se o estilo autoritário e o comportamento centrado nas pessoas, que apresentava os estilos de liderança participativo-democrático, participativo-consultivo e o liberal (ROBBINS et al., 2014).

Para Robbins (2014) o comportamento centrado em tarefas trabalha os aspectos mais técnicos e gasta esforços na realização das tarefas cotidianas. O comportamento é percebido como sendo provocado e guiado por metas da pessoa, que realiza um esforço para atingir determinado objetivo (TAMAYO; PASCHOAL, 2003). Para Damazzini; Ferreira, (2006); Robbins et al., (2014) o líder centrado em tarefas, tem o estilo autoritário, composta por líderes que decidem, e fixam as diretrizes sem qualquer participação do grupo, determina as providências para a execução das tarefas, à medida que se tornam necessárias. Para Botelho; Kroc (2010) a produtividade até é elevada, mas a realização das tarefas não é acompanhada de satisfação, ou seja, não há espaço para a iniciativa pessoal, gera conflitos, atitudes de agressividade, de frustração, de submissão e desinteresse, entre outras. É um tipo de liderança negativa, suas ações são baseadas em ameaças e punições (MUNIZ, 2004). Talvez este estilo seja muito duro para os dias de hoje, porém ainda é comumente visto no mercado e existem organizações que necessitam deste estilo de líder para progre$\operatorname{dir}$ (ROBBINS et al., 2014).

Diante da pesquisa apresentada pela Universidade de Michigan (EUA) para determinar quais características resultavam em uma liderança eficaz entre os anos de 1940 e 1950 os pesquisadores intensificou um resultado 
positivo, que o comportamento centrado no colaborador tem mais possibilidade de levar o grupo a um desempenho eficaz do que o comportamento centrado nas tarefas (GRIFFIN e MOORHEAD, 2006). Já que a liderança exerce influência no comportamento das pessoas com a finalidade de motivá-las e impulsioná-las a conquistar resultados (OLIVEIRA; PEREZ, 2015). O comportamento centrado em pessoas tem ênfase nas relações interpessoais. O líder que utiliza este comportamento está preocupado com o bem estar dos colaboradores, trata suas relações como de confiança, amigáveis e de apoio. Está mais sensível aos problemas de seus colaboradores e geralmente apresenta os estilos de liderança democrática (participativa e consultiva) e liberal (ROBIINS, 2014).

O estilo de liderança democrática busca o envolvimento dos colaboradores para o estabelecimento de estratégias de ação para alcançar metas, incentiva o trabalho em equipe para resolver problemas e discutir ideias para definir as tomadas de decisões (ROBIINS, 2014). Há uma formação de grupo, onde os líderes e seus colaboradores que passam a desenvolver comunicações espontâneas, francas e cordiais havendo sentido de responsabilidade e comprometimento pessoal (BOTELHO; KROM, 2010). Onde as diretrizes são debatidas e decididas pelo grupo, que é estimulada e assistida pelo líder (Ribeiro, 2009 Pereira, 2014). O estilo de liderança democrático também é chamado de liderança participativa ou consultiva, este tipo de liderança é voltado para as pessoas e há participação dos liderados no processo decisório (SILVA et al., 2011).

Por fim, o estilo de liderança liberal (laissez-faire), dá autonomia para que o colaborador tome suas decisões e trabalhe da maneira a acreditar ser a melhor para atingir suas metas e objetivos (ROBIINS, 2014). Na condição de liderança liberal (laissez-faire) a atividade de liderar foi mantida em um mínimo sendo que o líder permitia aos colaboradores trabalhar e brincar sem nenhuma supervisão (BATISTA; WEBER, 2012). É a liberdade total para as decisões grupais ou individuais, com participação mínima do líder (RIBEIRO, 2009, apud Pereira, 2014). $\mathrm{Na}$ qual o líder transfere para o grupo o processo de tomada de decisão cedendo o controle por completo ou optando por evitar encargos (POTTER, 2004 apud RIBEIRO et al., 2006).

Para utilizar cada estilo em determinada circunstância o líder deve ter percepção e sensibilidade para observar quais são as necessidades dos colaboradores, pois o gestor deve estar preparado para usar qualquer estilo que a situação exija (ROBBINS; DECENZO; WOLTER, 2014).

\section{PROCEDIMENTOS METODOLÓGICOS}

\subsection{Estudo de Caso}

A empresa "Instituição Financeira de Pinhais" está localizada no centro da cidade de Pinhais, Estado do Paraná, possui uma grande estrutura física, trabalha como um banco múltiplo e é referência no mercado em que atua. Possui inúmeras agências no país e no exterior e faz parte de um grande conglomerado de empresas. O tamanho desta organização possibilita o estudo de diversos casos sob variados pontos de vista. Nesta demanda, foi percebido que dentre os trinta colaboradores da agência de Pinhais, havia uma variação de motivação entre eles. O fato foi pesquisado por um dos colaboradores deste grupo no decorrer do final do ano de 2015 e início de 2016

Desta forma surgiu uma proposta de pesquisa que relacionou a forma de liderança dos gestores com a motivação dos liderados. A empresa possui onze gestores que lideram dezenove colaboradores. Isto dá a possibilidade para a identificação de quais são fatores que podem auxiliar a constante busca da sustentabilidade organizacional na empresa "entre os variados estilos de liderança e a relação, se existente ou não, sobre a motivação dos colaboradores". Pretendendo gerar informações que auxiliem em melhorias para esta empresa.

\subsection{Metodologia de pesquisa}

Para a produção deste artigo foi elaborada uma pesquisa de campo, onde primeiramente realizou-se a pesquisa bibliográfica em livros, artigos científicos publicados em revistas eletrônicas e congressos para a obtenção de conhecimento sobre conceitos, os quais incidem nas oportunidades identificadas no projeto. A pesquisa bibliográfica é importante para a determinação dos estilos de liderança dos gestores, para descobrir quais são os métodos eficazes de abordagem. Sendo também, essencial para elucidar teoricamente os conceitos de sustentabilidade organizacional, definir aspectos motivacionais e principalmente embasar e nortear a pesquisa de campo. E assim, com as pesquisas quantitativas colher os dados e diagnosticar possíveis soluções, se houverem, para o problema inicial.

Os métodos de pesquisa quantitativos descritivo na pesquisa consistem em investigações de pesquisa empírica cujo principal objetivo é o delineamento ou análise das características de fatos derivados da verificação de hipótese consistindo entre duas ou mais variáveis (MARCONI LAKATOS, 2007). A pesquisa científica através do método quantitativo-descritivo de verificação de hipótese tem 
como finalidade analisar as características dos estilos de liderança e a motivação dos colaboradores. O tema da pesquisa de campo fala sobre estilos de liderança como geradores de sustentabilidade organizacional, a delimitação do tema foi à relação dos estilos de liderança como geradores de motivação nos colaboradores e o objetivo geral era definir se os estilos de liderança geram resultados positivos. Para a coleta de dados foi estabelecido que todos os colaboradores eram público-alvo e que as questões seriam objetivas em relação ao tema. A tabulação foi efetuada através de gráficos permitindo a análise dos resultados.

A pesquisa realizada com a participação de todos os colaboradores da empresa. Sendo aplicadas duas versões, a primeira para gestores e a segunda para os demais colaboradores. Foi garantido o sigilo dos participantes e todos os colaboradores presentes participaram, havia dois colaboradores que estavam de férias. Este levantamento teve o objetivo de descobrir quais os estilos de liderança praticados na empresa, nas visões dos gestores e colaboradores, como os colaboradores estão motivados; como os gestores acreditam que seus colaboradores estão motivados e como os colaboradores gostariam que seus gestores liderassem.

Posteriormente foi efetuada a tabulação dos dados e o levantamento e questionamento dos resultados, chegando ao final da demanda proposta com uma análise teórica embasada em autores reconhecidos por suas pesquisas e o resultado sobre o tema inicial.

\section{ANÁLISE DE DADOS}

Com a aplicação da pesquisa qualitativa obtivemos um conjunto de informações, que foram convertidas e apresentadas em gráficos para uma melhor visualização e interpretação dos dados obtidos.

No primeiro Gráfico 1, perguntou-se para cada gestor, como ele considerava seu estilo de liderança. Obteve-se como resposta sendo $32 \%$ autoritário, $47 \%$ participativo e consultivo e $21 \%$ liberal, ao confrontar com o Gráfico 2 , que questionando, mas na perspectiva dos colaboradores. Com a pesquisa obteve-se as respostas $32 \%$ autoritário, $42 \%$ participativo e consultivo e $26 \%$ liberal. Com uma pequena margem de diferença conclui-se que as visões dos gestores e dos colaboradores são semelhantes em relação aos estilos de lideranças encontradas na empresa.
Gráfico 01: Classificação dos estilos de liderança na perspectiva dos gestores

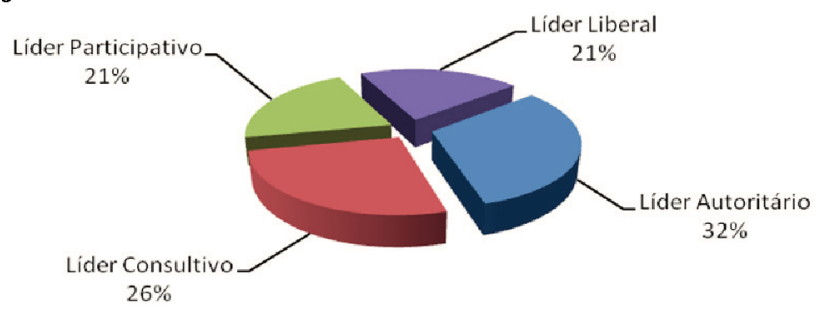

Fonte: Autor, (2016)

Gráfico 02: Classificação dos estilos de liderança na perspectiva dos colaboradores

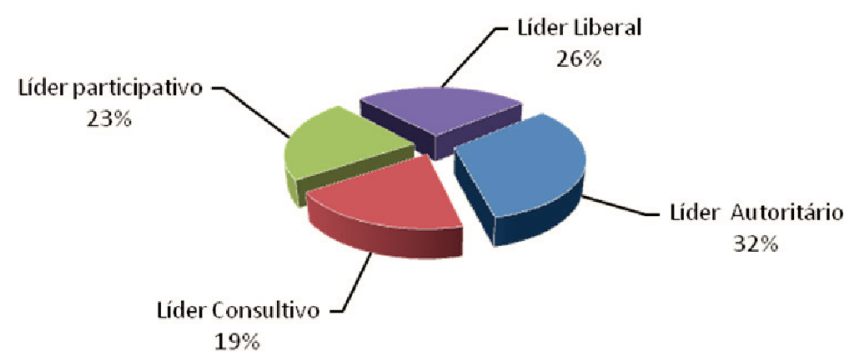

Fonte: Autor, (2016)

Com as informações dos Gráficos 1 e 2, fica evidente na agência da "Instituição Financeira de Pinhais" dentro dos quatros estilos de lideranças encontrados (Autoritário, participativo, consultivo e liberal) $32 \%$ são de líderes autoritários, que segundo (MUNIZ, 2004; DAMAZZINI; FERREIRA, 2006; ROBBINS et al., 2014), não tem uma boa aceitação dentre os colaboradores, pois estão centrados somente no cumprimento das tarefas.

O fato também esta evidenciado na ilustração do Gráfico 3, onde os colaboradores responderam que preferem trabalhar com todos os estilos de liderança, menos o estilo autoritário.

Por outro lado, o percentual de gestores com estilo participativo e consultivo é de no mínimo de $79 \%$, significando que os colaboradores possuem voz ativa para influenciar nas tomada de decisão. E o estilo de liderança liberal aparece com no mínimo $21 \%$, o que revela uma atitude de liberdade na realização das tarefas pelos colaboradores.

Gráfico 03: Estilos que motivaria os colaboradores

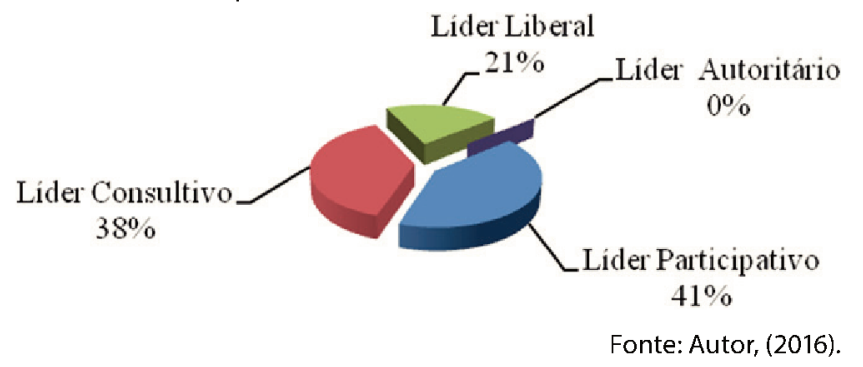


Relacionados com as definições teóricas dos estilos de liderança e a pesquisa aplicada, obteve-se dados que indicam que $68 \%$ do comportamento dos líderes são centrados em pessoas, através da liderança autoritária. Desta forma os dados apresenta a existência da preocupação dos gestores com relação à tratativa para com seus colaboradores.

O Gráfico 4, quando questionados sobre a motivação de seus colaboradores, os gestores responderam que $73 \%$ dos colaboradores estão motivados, contra $27 \%$ de colaboradores não motivados. No Gráfico 5 , os colaboradores responderam que $32 \%$ estão motivados contra $68 \%$ desmotivados, ou seja, uma grande discrepância da visão dos gestores para os colaboradores. Sendo este tema bem interessante, pois (PEDROSO et al., 2012) a motivação é uma força que impulsiona a realização de algo em prol de uma necessidade interna do indivíduo.

Neste caso evidencia-se que os líderes não conhecem as reais necessidades de seus colaboradores, uma vez que cada indivíduo é único e tem metas pessoais. O que realmente é preocupante, porque segundo as pesquisas, quase $70 \%$ dos gestores estão centrados em pessoas e não somente nas realizações das tarefas.

Gráfico 04: Motivação dos colaborados na visão dos gestores

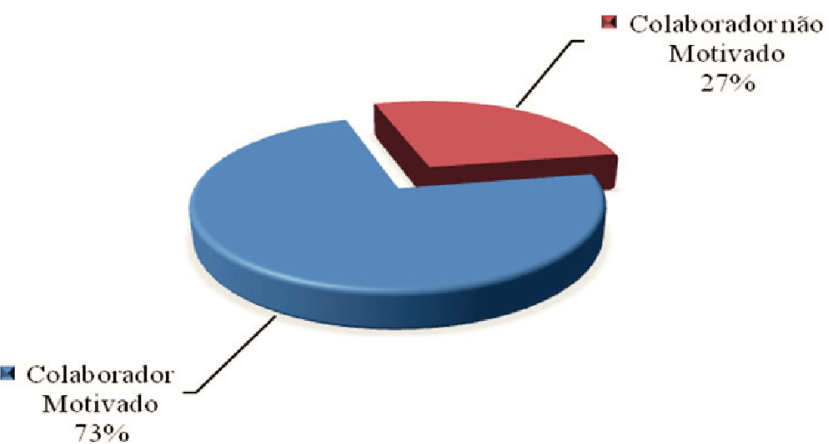

Fonte: Autor, (2016)

Gráfico 05: Motivação na visão dos Colaboradores

a Colaborador não Motivado $68 \%$

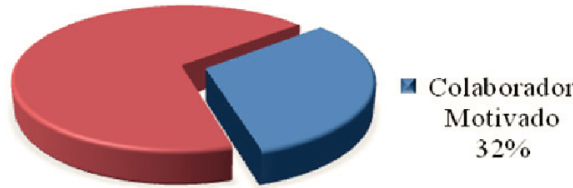

Fonte: Autor, (2016)

Neste caso, segundo as pesquisas teóricas, cabe ao gestor descobrir as necessidades dos colaboradores.

Podendo utilizar a teoria de Maslow, observando desde os níveis mais baixos da pirâmide das necessidades até o topo, a qual é a realização pessoal. Na etapa da realização pessoal, existem fatores como reconhecimento do seu trabalho, posição elevada na carreira, entre outros, que podem ser o fator de desmotivação quando não alcançadas. Depois que as necessidades dos colaboradores forem conhecidas, os líderes podem estimular motivos sociais em seus colaboradores. Podendo estreitar o relacionamento com os colaboradores e ainda contribuir para a sustentabilidade organizacional, uma vez que os colaboradores da empresa estão inseridos na sociedade não só nas relações de trabalho e recompensa, mas sim em verdadeiros relacionamentos sociais que vão além do horário de trabalho e levam a uma visão de trabalho em equipe para a obtenção de metas em comum.

O próximo resultado surge do questionamento de como influenciar os colaboradores. O Gráfico 6, ilustra as seguintes respostas, $18 \%$ dos líderes acreditam que não podem influenciá-los, 35\% influenciaria com recompensas, $35 \%$ influenciaria deixando os colaboradores participarem das decisões e $12 \%$ alterando o estilo de liderança. Os autores pesquisados salientam que os líderes não podem inserir motivação em seus colaboradores, porém podem e devem estimular motivações, através das necessidades existentes nos colaboradores. Se 35\% acredita que as recompensas podem dar resultados, eles não estão errados, mas a relação embasada somente em recompensa gerará uma relação de ganho e troca que pode acabar gerando um desgaste no trabalho, motivo o qual o colaborador não estaria motivado por suas necessidades e sim pela recompensa. Por outro lado, para sair da rotina é importante lançar desafios alcançáveis com premiações e esta ação bem planejada é considerada uma motivação cognitiva, onde estimula-se a necessidade de reflexão e analise de problemas.

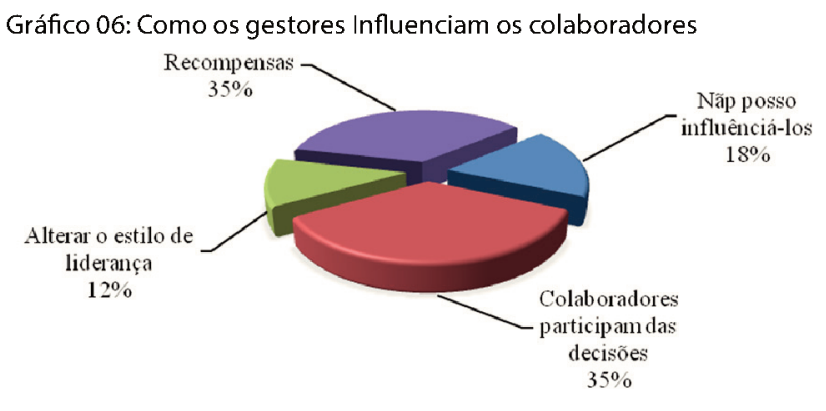

Observa-se ainda no Gráfico 6, que 35\% dos gestores acreditam que deixar os colaboradores participarem de decisões torna-os mais motivados. E realmente os estilos de liderança focados em pessoas, onde todos possuem voz ativa, tendem a ser mais aceitos e os liderados são 
mais felizes. Porém, para que tenha motivação, os gestores devem conhecer suas necessidades e precisam trabaIhar para que seus colaboradores sintam-se alcançando os seus limites para incorporá-los as metas da empresa e torna-las um objetivo em comum. Por fim, $12 \%$ responderam que alterando seus estilos de liderança alcançarão melhores resultados com seus colaboradores. As pesquisas dizem que o melhor estilo de liderança é o situacional, onde o gestor altera seu estilo de acordo com a situação e com os colaboradores, mas não deve ser feito sem o conhecimento profundo do perfil de seus colaboradores e principalmente dos estilos de liderança, sendo isto importante para não magoar ninguém e não acabar com o clima organizacional.

No Gráfico 7, apenas 36\% dos líderes acredita totalmente que a pressão de seus superiores para alcançar as metas organizacionais influencia em seu estilo de liderança, o que mostra a resiliência dos gestores no trato da pressão interna das metas da empresa, pois $64 \%$ não são influenciados ou são pouco influenciados pela pressão de superiores em seu estilo de liderança. Ilustrado pelo o Gráfico 8, mostra que $73 \%$ dos gerentes acreditam que as metas não são realistas e alcançáveis, então esta informação deve ser levantada em reuniões das agências ou superintendências para que os números sejam discutidos e readequados de maneira mais realistas, pois metas atingíveis geram maior aceitação pelos colaboradores.

Gráfico 07: Pressão dos superiores influência os líderes

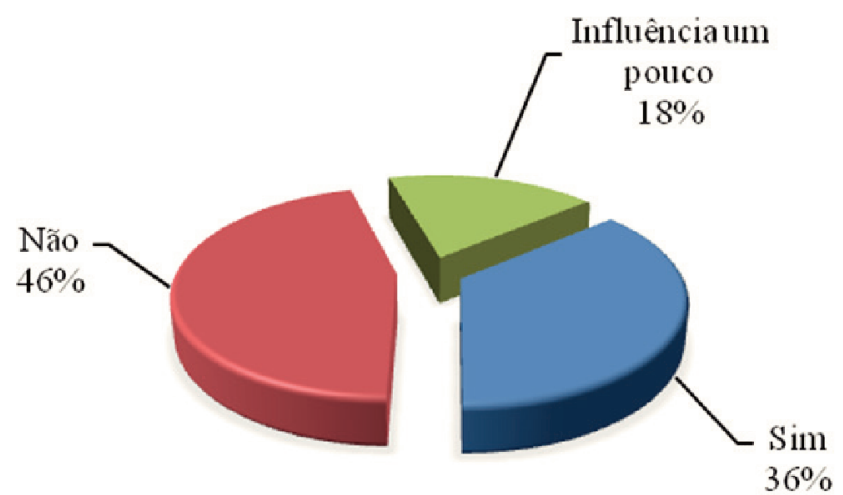

Fonte: Autor (2016).

Gráfico 08: Metas são realistas

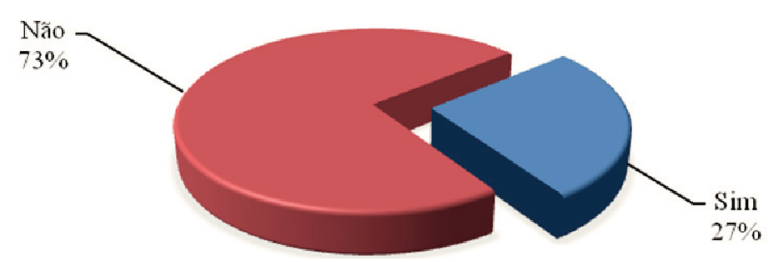

Fonte: Autor, (2016).
A última questão aplicada na "Instituição Financeira de Pinhais" trata da opinião dos líderes e colaboradores sobre ideias que melhorariam a motivação do grupo, sendo esta pergunta opcional. Foram dadas várias sugestões, como implantação de comissão por vendas sobre todos os produtos, horários mais flexíveis de atendimento, incentivo ao treinamento diário, propostas de redistribuição de cargos, entre outros. Concluindo que houve interesse em novas práticas de melhoria na empresa, evidenciando um sentimento de participação e de pertencimentos dos colaboradores para com a empresa, uma amostra de que "Instituição Financeira de Pinhais" caminha corretamente na busca de uma organização sustentável e com ferramentas para tornar as metas individuais e organizacionais em um objetivo em comum.

O tema estilos de liderança como geradores de sustentabilidade organizacional é muito limitado, pois somente os estilos de liderança não são fatores formadores de sustentabilidade organizacional. Os estilos de liderança em si são ferramentas de auxílio para a gestão dos líderes, mas o conhecimento das necessidades dos colaboradores e da empresa são condicionantes ao trabalho para o aumento da motivação dos colaboradores. E um colaborador motivado incorpora suas metas pessoais com as metas organizacionais, que é onde entra a sustentabilidade organizacional. Pois para uma empresa obter diferencial no mercado, ela deve pertencer à sociedade em que está inserida através da incorporação de seu papel como agente modificador de seu meio ambiente.

Os estilos de liderança geram resultados positivos sim e o que deve ser observado é que o perfil ideal do estilo de liderança é o situacional, onde o gestor através do conhecimento que possui altera seu estilo de liderança conforme a necessidade da situação.

\section{CONCLUSÕES}

A construção deste artigo realizou-se, através do tema estilos de liderança como geradores de sustentabilidade organizacional, proporcionou a identificação dos fatores que podem auxiliar a constante busca da sustentabilidade organizacional na empresa "Instituição Financeira de Pinhais", onde evidenciou-se a variação motivacional entre seus colaboradores, que na literatura reduz significativamente a produção da organização. A ideia original para relacionar os estilos de liderança com a motivação dos colaboradores determinou-se que a metodologia aplicada seria a pesquisa de campo com pesquisa quantitativa e utilização do método hipotético-dedutivo. 
Já na elaboração do referencial teórico surgiu a definição de sustentabilidade organizacional, onde fica evidente que a organização é parte integrante de seu ambiente recebendo influências internas e externas sendo alterada e alterando seu microuniverso. E com tamanha complexidade do tema foi evidenciado que os estilos de liderança são somente uma ferramenta de gestão que tem uma pequena participação no contexto do atingimento da sustentabilidade organizacional. Outro ponto da teoria é a motivação, que se traduz em uma força que um indivíduo dispensa para alcançar uma necessidade pessoal. E uma necessidade não pode ser criada por fonte externa, ou seja, um líder não pode motivar seu colaborador. O que pode ser feito é conhecer a necessidade do indivíduo e trabalhar para aumentar ou diminuir sua motivação em conquistá-la. É onde os gestores podem auxiliar seus colaboradores e em contrapartida transformar as metas organizacionais em um objetivo em comum, ou em uma necessidade em comum, já que segundo a teoria quando estamos unidos buscando a ajuda mútua, tendemos a nos unir em prol de objetivos em comum.

Na realização da pesquisa de campo o método foi alterado para quantitativo-descritivo de verificação de hipótese, para uma melhor adequação ao projeto. Pois existia a hipótese explicativa para o problema inicial sendo preciso verificar se realmente os estilos de liderança eram suficientes para motivar os colaboradores o que acabou se tornando apenas um dos fatores que auxiliam na motivação dos colaboradores. Na aplicação das pesquisas ocorreu tudo bem e apenas dois colaboradores não responderam por que estavam de férias. $E$ a tabulação de dados gerou oito gráficos onde foi possível cruzar informações relevantes para a análise do pleito.

$\mathrm{Na}$ análise de dados evidenciou-se, que a uma população em potencial de $35 \%$ dos gestores autoritários que podem trabalhar seu estilo de liderança para o situacional e centrar seu comportamento nas pessoas e suas necessidades. Outro ponto tem relação com as metas da empresa que não são atingíveis segundo a pesquisa e tendem a gerar desmotivação no grupo de trabalho.

Encontrou-se na empresa um grande percentual de gestores centrado em pessoas que demonstram se importar com seus liderados. E colaboradores comprometidos com a empresa mostrando um sentimento de participação e pertencimento. Evidenciando que a busca pela sustentabilidade organizacional está próxima e se faz necessário o aprimoramento de todos os colaboradores através de cursos e treinamentos sobre os temas abordados neste artigo, além de constantes reflexões sobre o papel da empresa e de cada colaborador como parte integrante desta organização.

Além das variáveis que podem ser utilizadas para o aperfeiçoamento dos líderes, como o caso da existência de $35 \%$ de gestores com perfil autoritário, os quais podem trabalhar para alterar o estilo de liderança para obter maior interação com seus colaboradores. Outro aspecto que pode ser trabalhado é a aproximação dos gestores com seus colaboradores, uma vez que o relacionamento é a chave para o conhecimento de seu próximo e para que isto ocorra à empresa deve investir em atividades descontraídas dentro e fora da jornada de trabalho para gerar maior aproximação entre todos os colaboradores.

O tema abordado gerou informações que podem ser utilizadas em treinamentos ou elaboração de um plano de ação para melhorar as práticas de gestão no quesito liderança, nesta agência. Em relação à sustentabilidade organizacional, a empresa está no caminho correto, pois seus gestores tem preocupação com seus colaboradores e utilizam em sua maioria o comportamento centrado em pessoas. Enfim, a agência tem condições reais de melhorar seu resultado.

\section{REFERÊNCIAS}

ABREU, Z. A motivação do agir Humano. Revista eletrônica Fundação Educacional São José. Vol. 1, №1. Artigo 4. ISSN: 2138-3098.

BARBIERI, U. Gestão de Pessoas nas Organizações - Conceitos Básicos e Aplicações. 1a ed. São Paulo: Atlas, 2016.

BATISTA, A.; WEBER, L. Estilos de liderança de professores: aplicando o modelo de estilos parentais. Psicologia Escolar e Educacional. 16(2), 299-307, 2012. Disponível em: <https://dx.doi.org/10.1590/S1413-85572012000200013>

BOTELHO, J.; KROM, V. Os estilos de lideranças nas organizações. XIV Encontro Latino Americano de Iniciação Científica e X Encontro Latino Americano de PósGraduação - Universidade do Vale do Paraíba, 2010.

CASSIMIRO, S.; FONTELES, A.; FARIAS, G. A liderança no contexto das organizações: Um estudo da persepção dos gestores da Colaço Martins Construções e Empreendimemntos LTDA no município de Beberibe/CE. $X$ Congresso Online - Administração 7 a 9 de novembro de 2013. 
COLARES, J. A contribuição Behaviorista para a administração. Saber Científico, Porto Velho, 1(2): 19-31, Jul./Dez. 2008.

DAMAZZINI, J.; FERREIRA, J. Estilo de liderança e influência exercida nos liderados. VI EDUCERE Congresso Nacional de Educação da PUCPR, 2006 PRAXIS - de 6 a 8 de Novembro de 2006.

FARAH, O.; CAVALCANTI, M.; MARCONDES, L. Empreendedorismo - Estratégia de Sobrevivência para pequenas Empresas. 1ª ed. São Paulo: 2012.

GIMENES, A.; TOLEDO, M.; ÁVILA, R.; PAULINO, P. Importância da liderança no desempenho dos colaboradores dentro das organizações. Disponível em: <https://www.inesul.edu.br/revista/arquivos/arq-idvol_33_1426538800.pdf> Acesso em 28 de mai. de 2016.

GODOI, C.; FREITAS, S.; CARVALHO, T. Motivação na aprendizagem organizacional: construindo as categorias afetiva, cognitiva e social. RAM, Rev. Adm. Mackenzie, V. 12, N. 2 . São Paulo, SP. MAR./ABR. 2011. p. 30-54 . ISSN 1678-6971.

GOMES, E.; MICHEL, M. A motivação de pessoas nas organizações e suas aplicações para obtenção de resultados. Revista Científica Eletrônica de Administração. Ano VII - Número 13 - Dezembro de 2007 - Periódico Semestral. ISSN: 1676-6822.

GONÇALVES, J. Os impactos das novas tecnologias nas empresas prestadoras de serviços. Revista de Administração de Empresas São Paulo, 34(1 ):63-81 Jan./ Fev. 1994.

GRIFFIN, R.; MOORHEAD, G. Fundamentos do Comportamento Organizacional. São Paulo: Ática, 2006.

HESKETH, J.; COSTA, M. Construção de um instrumento para medida de satisfação no trabalho. Rev. Adm. Emp., Rio de Janeiro, 20(3): 59-68, jul./ set. 1980.

LAS CASAS, A. Administração de Vendas. $8^{a}$ ed. São Paulo: Atlas, 2012.

MANCINI, S. Gestão com Responsabilidade Socioambiental. Tese (Doutorado) - Interunidades em Ciência Ambiental, Universidade de São Paulo, 2008.
MARCONI, M.; LAKATOS, E. Fundamentos de metodologia científica. $6^{\text {a }}$ ed. São Paulo: Atlas, 2007.

MARQUES, J. A teoria de Maslow na Motivação profissional. Disponível em: < http:// www.ibccoaching. com.br/portal/coaching-e-psicologia/piramide-maslow-motivacao-profissional/>. Acesso em 28 de mai. de 2016.

MATOS, J. A questão da razão como critério distintivo entre homem e animal. Filosofia Unisinos, 12(1):4855, jan/apr 201. Doi: 10.4013/fsu. 2011.121.04.

MULLER-GRANZOTTO, M.; MULLER-GRANZOTTO, R. Perls leitor de Freud, Goldstein e Friedlaender e os primeiros ensaios em direção a uma psicoterapia gestáltica. Estud. pesqui. psicol. [online]. 2007, vol.7, n.1, pp. 0-0. ISSN 1808-4281.

MUNCK, L.; DIAS, B.; SOUZA, R. Sustentabilidade organizacional: uma análise a partir da institucionalização de práticas coeficientes. REBRAE. Revista Brasileira de Estratégia, Curitiba, v. 1, n. 3, p. 285-295, set./dez. 2008.

MUNIZ, M. O papel do líder no gerenciamento das diferenças individuais. Monografia apresentada ao curso de MBA de Administração Judiciária da Fundação Getúlio Vargas, como requisitos para obtenção do Certificado de Especialização em Administração Judiciária. Rio de Janeiro, 2004.

MURRAY, E. Motivação humana. 5.ed. Rio de Janeiro: Zahar, 1983.

NABAIS, C. Homem/animal: a arte como anti-humanismo. In Abecedário de criação filosófica para o ensino médio, Omar Kohan, Walter e Muller Xavier, Ingrid (org). Belo Horizonte: Editora Autêntica, 2008. Acesso em: 30 de Maio de 2012. Disponível em: <http://cfcul.fc.ul.pt/ equipa/3_cfcul_elegiveis/catarina_nabais/homem\%20 animal.pdf>

OLIVEIRA J. Profissão Líder - Desafios e Perspectiva. $1^{\text {a }}$ ed. São Paulo: Saraiva, 2006.

OLIVEIRA, A.; PEREZ, O. Liderança eficaz: o poder e a influência de um líder no comportamento organizacional de uma empresa. Administração de Empresas em Revista v. 14, n. 15 (2015) ISSN: 2316-7548. 
OLIVEIRA, L.; NOVAES, D. A teoria da expectativa nas empresas: um estudo de caso'. Revista de Iniciação Científica versão eletrônica v.1, Jan.-Jun. 2011.

PEDROSO, D.; FRANÇA, N.; OLIVEIRA, S.; OSAWA, J. Importância da Motivação dentro das Organizações. Revista Ampla de Gestão Empresarial, Registro, SP, Ano 1, $N^{\circ} 1$, art. 5, p 60-76, out 2012, ISSN 2317-0727.

PEREIRA, A. A liderança como um fator de diferencial competitivo. Periódico Científico Negócios em Projeção V.5, N.1, 2014.

RABENHORST, E. O valor do homem e o valor da natureza. In: Filho, Agassiz Almeida; Melgaré, Plínio.. (Org.). Dignidade da pessoa humana. Fundamentos e critérios interpretativos. São Paulo: Malheiros, 2010, v. p. 21-38.

REEVE, J. Motivação e Emoção. $4^{\circ}$ ed. Rio de Janeiro: LTC, 2011.

RIBEIRO, M.; SANTOS, S.; MEIRA, T. (2006). Refletindo sobre liderança em Enfermagem. Escola Anna Nery, 10(1), 109-115. https://dx.doi.org/10.1590/

ROBBINS S.; DECENZO D.; WOLTER R. A Nova Administração. $1^{\text {a }}$ ed. São Paulo: Saraiva, 2014.

SAMPAIO, J. O Maslow desconhecido: uma revisão de seus principais trabalhos sobre motivação. R.Adm. São Paulo, v.44, n.1, p.5-16, jan./fev./mar. 2009.

SILVA, C.; PEIXOTO, R.; BATISTA, J. A Influência da liderança na motivação da equipe. Revista Eletrônica Novo Enfoque, ano 2011, v. 13, n. 13, p. 195 - 206.

SILVA, K.; FERNANDES, ALMEIDA, V.; DANDARO, F. Motivação om aumento da satisfação e melhoria de desempenho na empresa de materiais rodantes. Revista Eletrônica v. 04, n 1, p. 23-45, JAN-JUN, 2013. ISSN: 0486-6266.

SILVEIRA, M. Gestão da Sustentabilidade Organizacional: Inovação, Aprendizagem e Capital Humano. Campinas, SP: CTI (Centro de Tecnologia da Informação "Renato Archer"), 2012. ISBN 978-85-65163-00-2.

SKINNER, E; BELMONT, M. Motivation in the classroom: reciprocal effects or teacher behavior and student engagement across the school year. Journal of Educational Psychology, New York, v. 85, n. 4, p. 571-581, Dec. 1993.

SUSTENTABILIDADE EMPRESARIAL. Disponível em: $<$ http://www.suapesquisa.com/ecologiasaude/sustentabilidade_empresarial.htm>. Acesso em: 23 de maio de 2016.

TAMAYO, A.; PASCHOAL, T. A relação da motivação para o trabalho com as metas do trabalhador. Revista de Administração Contemporânea, 7(4), 33-54. https://dx. doi.org/10.1590/S1415-65552003000400003.

WERNER, W.; WERNER, I. Gestão do conhecimento: Ferramentas tecnológicas e portais do conhecimento para empresas desenvolvedoras de tecnologias de médio e pequeno portes. Terra e Cultura, ano XX, n³8 p.182-232 janeiro a junho de 2004. ISSN: 0104-8112. 